\title{
On Ruminococcus flavefaciens, a Cellulose-decomposing Bacterium from the Rumen of Sheep and Cattle
}

\author{
By A. KAARS SIJPESTEIJN* \\ Department of Bacteriology, University of Sheffield and Laboratorium voor \\ Microbiologie, Technical University, Delft, Holland
}

\begin{abstract}
SUMMARY: Two strains of Ruminococcus flavefaciens, an important cellulosedecomposing bacterium, were isolated, one from the rumen of a sheep, the other from the rumen of a cow. Pure cultures were obtained by using the dilution method in agar media containing a strip of filter-paper. These strictly anaerobic, Grampositive streptococci attack cellulose and cellobiose, but not starch, maltose, lactose or xylose. Only one strain could use glucose. Colonies on cellulose media were characterized by the formation of a yellow pigment; in cellobiose media the colonies were white. Growth on cellulose was favoured by addition of Clostridium sporogenes or a certain amount of sterilized medium in which $\mathrm{Cl}$. sporogenes had previously grown.

Estimations of the end-products of fermentation of cellulose and cellobiose showed that at least $25 \%$ of the carbon could be recovered as succinic acid, c. $23 \%$ as acetic acid and $c .10 \%$ as formic acid; ethanol was absent and gas formation very limited. A description of the genus and the species is given.
\end{abstract}

Our knowledge of the bacteria that effect the breakdown of cellulose in the rumen of ruminants is still very meagre. Hungate (1947) was the first to obtain pure cultures of several types of these bacteria, in the form of asporogenous rods or cocci. Using a similar technique the present author (1948) isolated from a bovine rumen a cellulose-decomposing streptococcus, to which the name Ruminococcus flavefaciens was given. This is a small Gram-positive, obligate anaerobic streptococcus which forms yellow colonies on filter-paper. This organism must be considered one of the predominant species of cellulosedecomposing bacteria in the rumen. As growth in pure culture was very poor, little information was then obtained about them and an analysis of the products of their metabolism was impossible. In combined culture with $\mathrm{Cl}$. sporogenes, however, cellulose was rapidly attacked by the streptococci, acetic and succinic acids being the main end-products. The present work was carried out with two other strains of Rum. flavefaciens, and more information obtained about the species.

During this investigation a further paper was published by Hungate (1950), in which he described more closely four bacterial types that play an important role in the decomposition of cellulose in bovine rumen. Two of these are cocci; it is not excluded that one of them is identical with Rum. flavefaciens.

\section{MATERIAL AND METHODS}

Strains. The present work was carried out with two strains of Rum. flavefaciens: strain $\mathrm{S}$ from the rumen of a fistulated sheep; strain $\mathrm{D}$ from the rumen of a slaughtered cow. Strain $S$ was investigated at the Department of

* Present address : Organisch Chemisch Instituut T.N.O. Utrecht, Holland. 
Bacteriology of Sheffield University, and strain D at the Laboratorium voor Microbiologie of the Technical University at Delft, Holland.

Cultivation. For cultivation and purification the dilution method in agar media (Sijpesteijn, 1948) was used in somewhat simplified form.

Conical flasks $(100 \mathrm{ml}$.) contained $25 \mathrm{ml}$. of a solution of the following composition (in $\%, w / v$ ): Davis's New Zealand agar (1.5), $\mathrm{K}_{2} \mathrm{HPO}_{4}(0.06)$, $\mathrm{KH}_{2} \mathrm{PO}_{4}(0 \cdot 04),\left(\mathrm{NH}_{4}\right)_{2} \mathrm{SO}_{4}(0 \cdot 04), \mathrm{NaCl}(0 \cdot 12), \mathrm{MgSO}_{4} \cdot 7 \mathrm{H}_{2} \mathrm{O}(0 \cdot 02), \mathrm{CaCl}_{2} \cdot 6 \mathrm{H}_{2} \mathrm{O}$ $(0.02)$. To each flask $19 \mathrm{ml}$. tap water was added. The medium was boiled out and a reducing agent added, either $25 \mathrm{mg}$. $\mathrm{Na}$ thiolacetate per flask in the case of strain $\mathrm{S}$, or $50 \mathrm{mg}$. L-cysteine $\mathrm{HCl}$ adjusted to $\mathrm{pH} \mathrm{7}$, for strain $\mathrm{D}$. After autoclaving, $3 \mathrm{ml}$. yeast autolysate and $3.5 \mathrm{ml} .7 \% \mathrm{NaHCO}_{3}$ were added per flask to give a final concentration of $6 \%(\mathrm{v} / \mathrm{v})$ and $0.5 \%(\mathrm{w} / \mathrm{v})$ respectively in the final liquid volume of $c .50 \mathrm{ml}$. The bicarbonate solution was sterilized by filtration. The filled flasks were put in a water-bath at $38-40^{\circ}$ and gassed for about $5 \mathrm{~min}$. with $\mathrm{CO}_{2}$ freed from traces of oxygen by passage over reduced copper turnings heated to $c .400^{\circ}$. The medium was subsequently distributed between six sterile tubes each containing a strip of Whatman no. 1 filter-paper. The medium remained liquid at the temperature of the water-bath. The New Zealand agar proved to be very useful in this procedure because it gelled at a lower temperature than Japanese agar at the same concentration. One of the tubes was then inoculated with $0.05 \mathrm{ml}$. rumen contents which had been previously filtered through muslin. The tube contents were mixed thoroughly by passing oxygen-free $\mathrm{CO}_{2}$ through the medium by means of a Pasteur pipette inserted between the plug and the wall of the tube, with the tip of the pipette at the bottom of the tube. Another tube was then inoculated with $0.5 \mathrm{ml}$. of the first tube, and, after mixing, $0.5 \mathrm{ml}$. was transferred to a third tube, and so on. After inoculation each tube was gassed with $\mathrm{CO}_{2}$ for about $4 \mathrm{~min}$. This proved sufficient to ensure saturation of the medium with $\mathrm{CO}_{2}$ (producing a final $\mathrm{pH} c .6 \cdot 6$ ), to remove traces of oxygen from the medium, and to replace the air above it by $\mathrm{CO}_{2}$. Methylene blue became decolorized almost immediately when added to this medium. During the final gassing procedure the plug was pushed into the tube, the Pasteur pipette withdrawn, and a rubber stopper quickly fitted to the tube. The tubes were then put into cold water to solidify the agar and after sealing the stoppers with paraffin-wax, incubated at $38^{\circ}$. This method is similar to that used by Hungate (1947, 1950), who, however, appears to take still more rigid precautions to prevent access of oxygen to his cellulose-decomposing bacteria. The method described above was adequate for the organisms we were dealing with.

Purification. The bacteria were purified as follows. Some days after inoculation with rumen contents colourless and yellow colonies which invariably consisted of cocci became visible on the paper strips. Yellow colonies of cellulose-decomposing rods such as Hungate (1950) described were never encountered. A yellow colony from the tube which had received the most dilute inoculum was used for each transfer. The bottom was cut from the tube und the agar column pushed out into a sterile Petri dish. The attacked strip of paper was then lifted from the agar with a pair of forceps and placed in another 
Petri dish on a layer of agar. As the organisms do not destroy the paper completely a yellow colony could then easily be picked out with a needle and transferred into a tube of fresh medium.

Strain $\mathrm{S}$ was subcultured from one of three yellow colonies obtained by inoculation of a tube with $0.003 \mathrm{ml}$. rumen liquid. It was pure after six serial transfers. Microscopically, contaminants were noticeable neither in the agar nor in the yellow colonies. Moreover, pieces of the agar or the filter-paper did not give rise to any growth after anaerobic incubation in peptone broth or meat medium.

Strain D was obtained from a tube that had been inoculated with $0.00045 \mathrm{ml}$. rumen liquid. On the paper strip three yellow colonies and one colourless colony developed. A pure culture was obtained after eight transfers from one of the yellow colonies. Since growth became very scanty as the culture was purified, the medium was modified as described below. The purity of the culture was checked microscopically as well as by incubation in peptone broth.

\section{CULTURAL CHARACTERISTICS AND CULTIVATION}

\section{Growth on cellulose}

Morphologically, strains S and D resembled closely the previously described (Sijpesteijn, 1948) strain G of Rum. flavefaciens. They were Gram-positive, catalase-negative streptococci with chains of 2,4 or 8 cells; cell diameter 0.8-0.9 $\mu$ (PI. 1, fig. 1). In strain D chain formation was less pronounced than in the other strains and single cocci were observed. Capsules were not noticed in strain $\mathrm{S}$, but were frequent in strain $\mathrm{D}$. Growth on cellulose was accompanied by pale yellow pigmentation of the paper strip, which was never so completely digested that holes were formed.

The growth of both these strains was better than that of strain G had been, although the filter-paper and the agar used at present are not superior for strain $\mathbf{G}$ to those previously used. Growth of the purified strains S and D was not so good as in the initial subcultures when many contaminants were still present. We return to this problem below.

Growth occurred in agar media with filter paper or finely divided cellulose, prepared according to Scales (1916), Fuller \& Norman (1942), or Hungate (1947). Cotton-wool and cellophan were also attacked.

About 10 days after inoculation the cultures showed a remarkable phenomenon. Tiny white colonies became visible in the agar adjacent to the paper strip. Their diameter never exceeded $c .0 .3 \mathrm{~mm}$. and they grew within some $5 \mathrm{~mm}$. of a colony on filter paper. Their size was larger the nearer they were to the paper. Microscopically, they only differed from the cellulose bacteria by their longer chains. The occurrence of minute secondary colonies was described for strain G (Sijpesteijn, 1948), and it was then shown that transfer of such a colony to the usual cellulose medium gives rise once more to many yellow colonies on the paper. Obviously the colonies consisted of cellulose-decomposing bacteria, and we assume that they grew on account of a diffusible substance produced from cellulose by the parent colony. Part of the products 
of the activity of the cellulolytic enzymes probably escapes immediate fermentation and diffuses into the medium. It seems unlikely that this substance should be glucose, the final product of hydrolytic breakdown of cellulose, for glucose was not attacked by one of the strains. It might well be cellobiose, which was an excellent substrate for both strains.

\section{Carbohydrate utilization}

Cellobiose. Both strains grew excellently in the agar medium with $0.1 \%$ cellobiose added instead of filter-paper. In very sparsely inoculated tubes the disk-shaped white colonies often showed a diameter of some $5 \mathrm{~mm}$. after c. 8 days growth. Upon transfer to a cellulose medium the ordinary yellow colonies developed again.

Cells of strain $\mathrm{S}$ grown on cellobiose agar differed microscopically from the cellulose-grown cells in that the chains were considerably longer, sometimes containing over 100 individuals (Pl. 1, fig. 2). With filter-paper as a substrate, chain length was apparently limited by the size of the fibres. Strain $\mathbf{D}$ showed about the same microscopical picture whether grown on cellulose or cellobiose (Pl. 1, fig. 3).

Colonies grown on cellobiose lacked the yellow pigment which is characteristic of growth on filter paper. The following phenomenon illustrates this: when a tube contains both cellobiose $(0.1 \%)$ and a strip of filter paper, some of the white colonies in the agar may touch the filter paper as they grow. In these cases one observes that at the place of contact the filter paper turns yellow and from that point the yellow coloration spreads gradually over a limited area of the paper. This is particularly striking in the higher dilutions where the colonies are fewer but much larger.

Glucose. Strain D grew readily in the agar medium with $0.1 \%$ Seitzfiltered D-glucose (British Drug Houses Ltd., Analar). White disk-shaped colonies became visible in the agar, usually 2-3 days after inoculation; they appeared, however, to remain smaller than those grown in presence of cellobiose. Upon transfer to a cellulose -medium this latter substance was readily attacked. Strain $\mathrm{S}$ did not grow in a $\mathbf{0 . 1} \%$ glucose medium (Kerfoot's pure bacteriological glucose used).

Other carbohydrates. Strains S and D did not grow on $0.1 \%$ lactose, $0 \cdot 1 \%$ maltose or $\mathbf{0 . 5} \%$ starch. Strain D did not attack D-xylose $(0 \cdot 1 \%)$.

\section{Maintenance of cultures}

Cellobiose was an excellent substrate for maintenance of the cultures. This was especially so because of the large size of the colonies and the ease with which they could be handled; a few colonies could be sucked out of the agar by means of a Pasteur pipette and blown out into a tube of fresh medium. The original tube could then be re-stoppered after thoroughly gassing the space above the agar with $\mathrm{CO}_{2}$, and could still be used for other transfers. Many serial transfers were made in cellobiose medium; the ability to attack cellulose was not lost thereby. It was found advisable to transfer the organisms every 
7-10 days. When 3- to 4-week old cultures had to be transferred, a very large inoculum was required.

\section{Attempts to improve growth}

For strain $\mathrm{G}$ it was found accidentally that the colonies became much larger if grown simultaneously with $\mathrm{Cl}$. sporogenes. Though less pronounced, this effect was also observed for the strains $\mathbf{S}$ and $\mathbf{D}$. The growth-promoting effect of $C l$. sporogenes was exerted over some distance, since a stab at $c .5 \mathrm{~mm}$. from the paper strip was as efficient as a suspension of these bacteria throughout the agar, suggesting that a diffusible factor was involved.

In experiments with strain $\mathbf{D}$ proof was obtained that the beneficial effect of Cl. sporogenes was due to its adding growth-promoting material to the medium rather than removing an inhibitory substance. When the number of contaminating species had been decreased to 3 or 4 , growth of strain $D$ became exceedingly poor. Addition of $\mathrm{Cl}$. sporogenes to the medium was very effective in this stage. $\mathrm{Cl}$. sporogenes was then grown for 5 days anaerobically on $20 \%$ yeast autolysate; $50 \mathrm{ml}$. of this culture were centrifuged to remove the bulk of the bacteria and the supernatant was filtered through a Seitz filter. Inclusion of $9 \mathrm{ml}$. of this sterile filtrate in $50 \mathrm{ml}$. medium, \pm the usual $6 \%$ yeast autolysate, greatly favoured growth of strain $\mathbf{D}$; the colonies grew more quickly and from a more diluted inoculum than without this addition. $\mathbf{A ~ p H}$ effect is excluded here, because the culture filtrate had the same $\mathrm{pH}$ as the usual medium. The same beneficial effect was obtained when the medium on which Cl. sporogenes had grown was sterilized by autoclaving. In this altered medium strain D was readily purified. Once pure, the strain grew well again in the usual medium, the addition of filtrate being no longer essential, though it still had a slightly beneficial effect. Thus $C l$. sporogenes seems to produce material which is necessary for growth of Rum. flavefaciens. Cl. sporogenes is not specific in this, and certain other bacteria also have a beneficial effect (Sijpesteijn, 1948). Sufficient of the factor is present in untreated yeast autolysate to allow almost optimal growth of strains $\mathbf{S}$ and $\mathbf{D}$ in pure culture in a medium with $6 \%$ yeast autolysate; for strain $G$ these conditions seemed to be suboptimal. We may assume that in impure cultures competition of contaminants for this factor sometimes makes an extra supply necessary. When cellobiose was used as a substrate for strain D growth was very good, irrespective of the presence of sterile filtrate of a $\mathrm{Cl}$. sporogenes culture.

The yellow pigment accompanying growth on cellulose is much intensified by the presence of $C l$. sporogenes or sterile culture filtrate. In cellobiose media the colonies appeared white on the usual medium, but in the presence of the $\mathrm{Cl}$. sporogenes culture filtrate large colonies appeared slightly yellow.

With regard to the identity of the active material negative results only have been obtained. Experiments with strain $G$ had already shown that addition of a variety of compounds (a mixture of aneurin, riboflavin, nicotinamide, Ca-pantothenate, pyridoxin, $p$-aminobenzoic acid, $i$-inositol, biotin; peptone; Bacto 'Casamino' acids; sterile rumen liquor; cobalt; etc.) did not produce the same effect as $\mathrm{Cl}$. sporogenes. The addition of folic acid (Ashe 
Laboratories) was tested on strain $\mathbf{D}$ during its worst period of growth; $0.01-0.30 \mu \mathrm{g} . / 6 \mathrm{ml}$. usual deficient medium gave no better growth. A highly concentrated preparation of vitamin $B_{12}$ (kindly supplied by Dr W. F. J. Cuthbertson, Glaxo Laboratories) used at $0 \cdot 2 \mu \mathrm{g}$. vitamin $\mathrm{B}_{12} / 5 \mathrm{ml}$. medium showed no growth promotion with strain $\mathbf{S}$.

\section{METABOLIC EXPERIMENTS}

The only previous information about the products of cellulose decomposition by Rum. flavefaciens was that obtained with strain G in combined culture with Cl. sporogenes (Sijpesteijn, 1948). The end-products found in $100 \mathrm{ml}$. mineral medium $+6 \%$ yeast autolysate + filter-paper + bicarbonate saturated with pure $\mathrm{CO}_{2}$ as a buffer, were: total volatile acids $4.78 \mathrm{mmol}$. (namely $0.94 \mathrm{mmol}$. formic acid, $3.26 \mathrm{mmol}$. acetic acid and $0.58 \mathrm{mmol}$. butyric acid), succinic acid $2.41 \mathrm{mmol}$, lactic acid $1.12 \mathrm{mmol}$. The amount of filter-paper decomposed was $4 \cdot 15 \mathrm{mmol}$. (calculated as glucose).

Two experiments were now carried out with strain $S$, on cellulose and on cellobiose respectively. No quantitative experiments were carried out with strain D.

Methods of cultivation. The experiments were conducted in a spherical flask with a long neck so that it could be gassed with $\mathrm{CO}_{2}$ and stoppered. On the lower part of the neck a calibration mark was made to indicate the volume of $130 \mathrm{ml}$. liquid contents. The medium contained the same salts as mentioned above, with $0.02 \% \mathrm{Na}_{2} \mathrm{~S} .9 \mathrm{H}_{2} \mathrm{O}$ instead of $\mathrm{Na}$ thiolacetate, $0.5 \% \mathrm{NaHCO}_{3}$, $5 \%$ yeast autolysate (prepared from $1 \mathrm{~kg}$. baker's yeast with 11 . water) and either a weighed amount of Whatman no. 1 filter-paper cut into pieces, or $0.3 \%$ cellobiose. The liquid sterile ingredients (total volume $c .150 \mathrm{ml}$.) were mixed in a $200 \mathrm{ml}$. flask by thorough gassing with $\mathrm{CO}_{2}$ immediately after autoclaving. The fermentation flask containing a little water was autoclaved separately and the water poured out; in the cellulose experiment the paper was autoclaved in this flask. After gassing the flask with $\mathrm{CO}_{2}$, the medium was poured in to the $130 \mathrm{ml}$. mark (the remaining volume of medium being kept for estimation of initial reducing value) and the flask re-gassed. The inoculum (not less than c. $10 \mathrm{mg}$. well-attacked filter-paper) was put into the flask, and after further gassing the flask was stoppered and sealed. During the gassing the flask was kept in a water bath at $c .40^{\circ}$ in order to attain the proper gas pressure.

Usually it took a few days before any indication of growth was visible. In the flask with cellulose, growth started around the piece of paper used as inoculum and gradually spread from there. The flask was stirred periodically to aid attack on other portions of the paper. The incubation period was 13 days for the cellulose and 7 days for the cellobiose experiment; the rate of fermentation probably soon slowed owing to increasing acidity of the medium. After fermentation, the purity of the cultures was checked by anaerobic incubation of a few drops in meat medium and in peptone broth, and by microscopical examination.

Analytical methods. The amount of cellulose fermented was found by 
estimating the initial and the final dry weight of the paper. The former was computed from the total initial weight of the paper and a dry-weight estimation of a measured sample of it. The inoculum of $c .10 \mathrm{mg}$. paper was added to the initial weight, an error of a few $\mathrm{mg}$. being unavoidable here. At the end of the experiment, the contents of the flask were filtered through a sintered-glass G3 filter to collect the cellulose residue, which was washed on the filter and its dry-weight measured.

The reducing value was estimated before and after fermentation by oxidation with ferricyanide and titration with ceric sulphate (Hassid, 1937). A $5 \mathrm{ml}$. sample was first treated with $\mathbf{0 . 5} \mathrm{ml}$. saturated lead acetate to precipitate protein, and subsequently with $1.0 \mathrm{ml}$. saturated $\mathrm{Na}_{2} \mathrm{HPO}_{4}$ to precipitate excess lead acetate. The estimation was carried out on the supernatant after centrifuging. The method was standardized beforehand on recrystallized cellobiose (Light) and glucose (British Drug Houses Ltd., Analar), giving mean values of $2.47 \mathrm{ml}$. $0.01 \mathrm{~N}$ ceric sulphate $/ \mathrm{mg}$. cellobiose, and $3.06 \mathrm{ml}$. $0.01 \mathrm{~N}$ ceric sulphate/mg. glucose. The amount of cellobiose decomposed was calculated from the difference of initial and final reducing values of the medium. Succinic acid was estimated manometrically by means of succinic dehydrogenase (Krebs, 1937). Volatile fatty acids were obtained by steam distillation. After destruction of any formic acid by distillation in presence of mercuric sulphate (Friedemann, 1938), chromatograms were made to identify other acids (Elsden, 1946).

No attempt was made to estimate the gaseous metabolic products. Agar cultures showed that only very little gas was produced, part of which must have been due to $\mathrm{CO}_{2}$ freed from bicarbonate buffer by accumulating acids. The production of any large amounts of metabolic $\mathrm{H}_{2}$ or $\mathrm{CO}_{2}$ seems unlikely.

Results. The results obtained are listed in Table 1 . The main end-product in terms of carbon recovery was succinic acid; $0.5 \mathrm{mmol}$. appeared to be produced per mmol. $\mathbf{C}_{6}$-unit fermented. Propionic and butyric acids were absent. Besides acetic acid, another volatile acid was present which was destroyed in the Friedemann distillation. Though proof is lacking, it seems probable that this was formic acid; in Table 1 the difference between the value for total volatile acids and the titration value after Friedemann distillation is expressed accordingly.

In the experiment with cellulose as substrate there was a slight initial reducing value due to the yeast autolysate present in the medium. After fermentation this value was somewhat higher. Thus a small amount of reducing substance was produced during fermentation. In Table 1 this increase in reducing value is expressed in terms of cellobiose.

The products found do not account for all the carbon fermented. In the pure-culture fermentations, acetic and formic acids represented 23 and $10 \%$ respectively and succinic acid $\mathbf{2 5 - 3 3} \%$. The latter value depends on whether the $\mathrm{CO}_{2}$ required in the formation of succinic acid from a $\mathrm{C}_{3}$-intermediate is entirely supplied as bicarbonate from the medium or whether it can be pictured as metabolic $\mathrm{CO}_{2}$ that is re-utilized. Changes in the $\mathrm{CO}_{2}$-content of the medium were not determined. 
Table 1. Products of fermentation of cellulose and cellobiose by Ruminococcus flavefaciens strain $S$

(Mineral medium with $5 \%(v / v)$ yeast autolysate and $0.5 \%(w / v) \mathrm{NaHCO}_{3}$, saturated with pure $\mathrm{CO}_{2}$.)

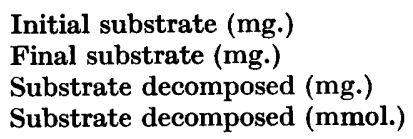

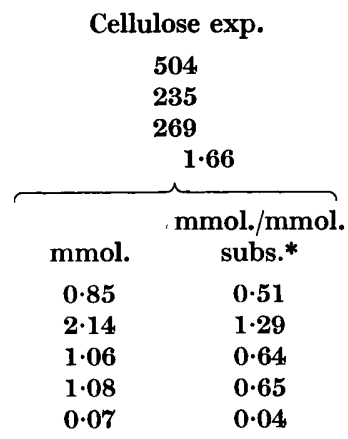

Cellobiose exp.

\begin{tabular}{|c|c|}
\hline \multicolumn{2}{|c|}{$\begin{array}{r}433 \\
82 \\
351 \\
1 \cdot 03\end{array}$} \\
\hline mmol. & $\underset{\text { subs.* }}{\mathrm{mmol} . / \mathrm{mmol}}$ \\
\hline 1.02 & 0.50 \\
\hline $2 \cdot 67$ & $1 \cdot 31$ \\
\hline 1.2 & 0.58 \\
\hline 1.5 & 0.73 \\
\hline - & - \\
\hline
\end{tabular}

* mmol. subs. $=$ mmol. substrate decomposed expressed in glucose units.

A search for other metabolic products showed that ethanol was absent (method of Conway, 1947). The culture medium gave, however, a weak positive Voges-Proskauer reaction, indicating the presence of small amounts of acetylmethylcarbinol. It seems possible that lactic acid is also an end-product; it was found in the combined culture of strain $\mathbf{G}$ with $C l$. sporogenes (Sijpesteijn, 1948). No lactic acid estimation could be made in the fermentation liquid of the pure culture S. Attempts to estimate the end-products of cellulose decomposition by strain $\mathbf{S}$ in a medium buffered with phosphate and gassed with $\mathrm{N}_{2}+5 \% \mathrm{CO}_{2}$ were given up because growth was very scanty.

\section{DISCUSSION}

Hungate (1950) reported yellow cocci which he isolated from the rumen. Though morphologically these organisms resembled our bacteria, there is a striking difference in the end-products of fermentation. The organisms grown by Hungate for 180 days in a medium with phosphate as buffer gave the following products : $0.307 \mathrm{mmol}$. $\mathrm{CO}_{2}, 0.264 \mathrm{mmol} . \mathrm{H}_{2}, 0.55 \mathrm{mmol}$. acetic acid, $0.252 \mathrm{mmol}$. ethanol, $0.68 \mathrm{mmol}$. lactic acid, traces of succinic acid; $80.0 \mathrm{mg}$. cellobiose ( $=0 \cdot 234 \mathrm{mmol}$.) accumulated and $259 \cdot 6 \mathrm{mg}$. cellulose $(=1 \cdot 60 \mathrm{mmol}$. calculated as glucose) disappeared. Essentially the same figures were found in a second experiment, which lasted 67 days. These results differ greatly from the present ones, but it must be stressed that the two sets of experiments were conducted under very different conditions with regard to the availability of $\mathrm{CO}_{2}$. It seems likely that Hungate's experiment was run without addition of $\mathrm{CO}_{2}$, whereas the present experiments took place in a bicarbonate medium saturated with $\mathrm{CO}_{2}$. These different conditions may perhaps account for the observed qualitative and quantitative differences in the end-products. Certainly it seems not unlikely that the $\mathrm{CO}_{2}$ pressure affects the yield of succinic acid and thus of other products. Unfortunately our attempts to investigate this failed. Very little information is available on the effect of the 
$\mathrm{CO}_{2}$ pressure on the composition of the end-products of different bacteria. Johns (1949), with Veillonella gazogenes, found that the $\mathrm{CO}_{2}$ pressure greatly influenced the yield of propionic acid, a decarboxylation product of succinic acid, in a lactate medium. On the other hand, the figures of Hungate (1950) for Bacteroides succinogenes show only a very slight effect. Thus it is not possible to decide at present whether the yellow coccus with which Hungate worked is identical with Rum. flavefaciens.

With regard to the fate of the observed end-products in the rumen the following may be said. In the rumen the $\mathrm{CO}_{2}$ pressure is usually high (c. 35-70\% partial pressure) so that the fermentation products should be similar to those found in the present experiments. Recent investigations have shown that succinic acid is rapidly decarboxylated in the rumen to propionic acid (Elsden \& Sijpesteijn, 1950) which is not further metabolized. Like the acetic acid found in the present experiments, propionic acid accumulates in in vivo and in vitro fermentations of cellulose by the rumen population (Elsden, 1945; Marston, 1948). From the rumen these acids directly enter the blood stream of the animal and undergo further conversions in its tissues (cf. Elsden \& Phillipson, 1948). It seems unlikely that the third metabolic product, formic acid, is stable in the rumen, but the mode of its transformation there has not yet been cleared up. Lactic acid may be one end-product of cellulose decomposition by Rum. flavefaciens; it is converted in the rumen into propionic acid and acetic acid (Elsden, 1945).

The fact that one of the present strains (S) does not grow in a glucose medium but can do so in cellulose and cellobiose media, is noteworthy. A similar observation has been made for other cellulose-decomposing bacteria (Hungate, 1947, 1950; McBee, 1948, 1950). Stanier (1942) and Enebo (1949) reported cellulose-decomposing organisms which attacked cellulose and cellobiose at much greater rates than they did glucose.

\section{CLASSIFICATION}

In 1948 the author proposed a new genus, Ruminococcus, in the tribe Streptococceae of the family Micrococcaceae according to the classification of Kluyver \& van Niel (1936). The name Ruminococcus flavefaciens was proposed for the present species. The description of the genus and the species follows here including some additional data.

\section{Description of the genus Ruminococcus}

Spherical cells; Gram-positive; generally in chains or pairs; non-motile; no endospores. Cellulose and other carbohydrates fermented with production of large amounts of succinic acid. Anaerobic.

The type species is Rum. flavefaciens.

Description of the species Ruminococcus flavefaciens

Morphology : cells almost spherical, diameter $0 \cdot 8-0 \cdot 9 \mu$. ; generally in chains or pairs; a yellow pigment is produced on cellulose. Utilizable carbon sources: 
cellulose, cellobiose, glucose used by certain strains; maltose, lactose, xylose, and starch not used. Catalase-negative. Obligate anaerobe. Mesophilic.

Source and habitat: occurs in vast numbers in rumen of cattle and sheep, and probably also in that of other ruminants and in caecum and colon of herbivorous mammals.

I am indebted to the British Council for a scholarship in England and wish to thank Dr S. R. Elsden for much advice and interest in the work and Prof. C. P. Beattie for hospitality in his Department. I am grateful to Prof. A. J. Kluyver for hospitality in the Laboratorium voor Microbiologie at Delft. My thanks are due to Mr J. A. Schuur and to Mr H. R. Veenhoff for taking the micrographs and photographs, respectively.

\section{REFERENCES}

Conway, E. J. (1947). Microdiffusion Analysis and Volumetric Error, 2nd ed. London: Crosby Lockwood.

ELSDEN, S. R. (1945). The fermentation of carbohydrates in the rumen of the sheep. J. exp. Biol. 22, 51.

ElsDen, S. R. (1946). The application of the silica gel partition chromatogram to the estimation of volatile fatty acids. Biochem. J. 40, 252.

Elsden, S. R. \& Phillipson, A. T. (1948). Ruminant digestion. Ann. Rev. Biochem. 17,705 .

Elsden, S. R. \& Sispesteijn, A. KaArs (1950). The decarboxylation of succinic acid by washed suspensions of rumen bacteria. J. gen. Microb. 4, xi.

ENEBo, L. (1949). On the formation of reducing sugars in thermophilic cellulose fermentation. Acta chem. scand. 3, 975.

Friedemann, T. E. (1938). The identification and quantitative determination of volatile alcohols and acids. J. biol. Chem. 123, 161 .

Fuller, W. H. \& Norman, A. G. (1942). A cellulose-dextrin medium for identifying cellulose organisms in soil. Proc. Soil Sci. Soc. Amer. 7, 243.

HASSID, W. Z. (1937). Determination of sugars in plants. By oxidation with ferricyanide and ceric sulphate titration. Industr. Engng Chem. (Anal. ed.), 9, 228.

Hungate, R. E. (1947). Studies on cellulose fermentation. III. The culture and isolation of cellulose-decomposing bacteria from the rumen of cattle. J. Bact. 53,631 .

Hungate, R. E. (1950). The anaerobic mesophilic cellulolytic bacteria. Bact. Rev. 14, 1.

JoHns, A. T. (1949). Mechanism of propionic acid formation in bacterial fermentation. Nature, Lond., 164, 620.

Kuuyver, A. J. \& Niel, C. B. van (1936). Prospects for a natural system of classification of bacteria. Zbl. Bakt. (2. Abt.), 94, 369.

Krebs, H. A. (1937). The role of fumarate in the respiration of Bacterium coli commune. Biochem. J. 31, 2095.

MCBEE, R. H. (1948). The culture and physiology of a thermophilic cellulosefermenting bacterium. J. Bact. 56, 653 .

McBeE, R. H. (1950). The anaerobic thermophilic cellulolytic bacteria. Bact. Rev. 14, 51.

Marston, H. R. (1948). The fermentation of cellulose in vitro by organisms from the rumen of sheep. Biochem. J. 42, 564 .

Scales, F. M. (1916). A new method of precipitating cellulose for cellulose agar. Zbl. Bakt. (2. Abt.), 44, 661. 
Journal of General Microbiology, Vol. 5, No. 5

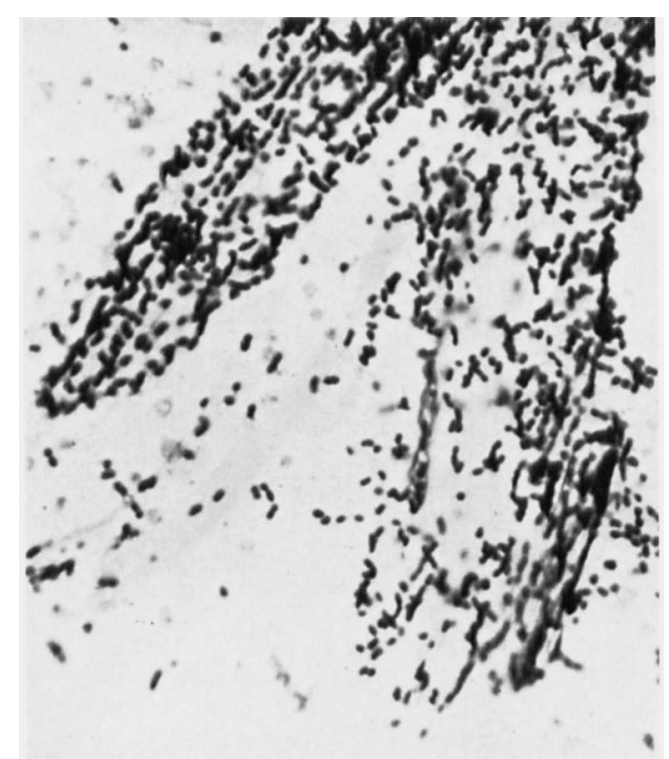

Fig. 1

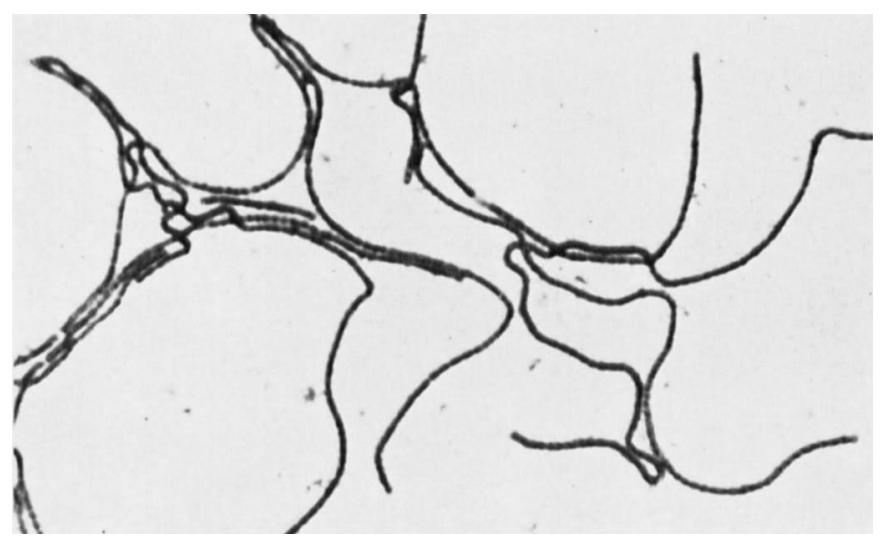

Fig. 2

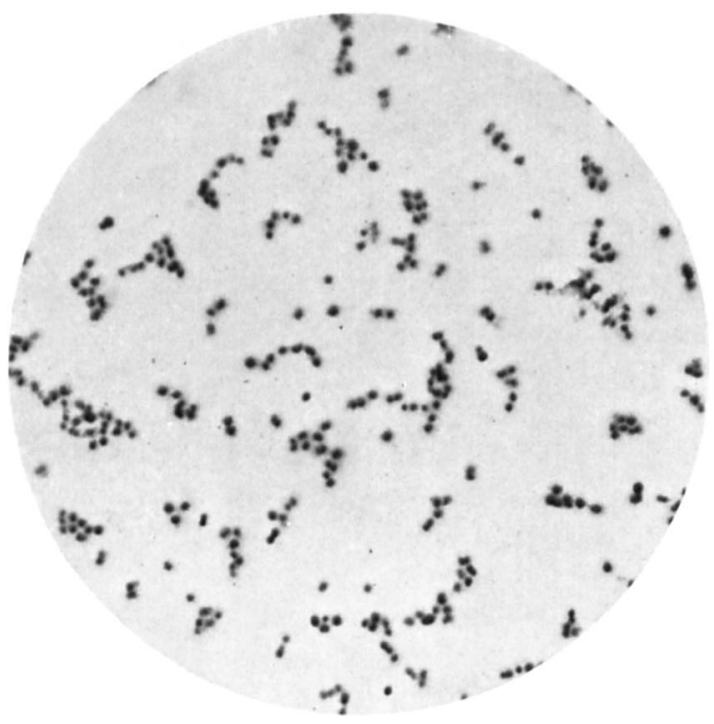

Fig. 3

A. K. SiJpesteiJn-ON Ruminococcus flavefaciens. Plate 1 

SiJPESTEIJN, A. KAARS (1948). Cellulose-decomposing bacteria from the rumen of cattle. Thesis. Leiden University. With a summary in Antonie van Leeurvenhoek J. Microbiol. Serol. 15, 49 (1949).

Stanier, R. Y. (1942). The cultivation and nutrient requirements of a chytridiaceous fungus, Rhizophlyctis rosea. J. Bact. 43, 499.

\section{EXPLANATION OF PLATE}

Fig. 1. Ruminococcus flavefaciens strain D on filter-paper fibres grown in agar medium for 5 days. Methyl violet stain; $\times 1000$.

Fig. 2. Rum. flavefaciens strain $\mathrm{S}$; from $0.1 \%$ cellobiose agar after 4 days. Gram stain; $\times 1000$.

Fig. 3. Rum. flavefaciens strain D; from $0 \cdot 1 \%$ cellobiose agar after 6 days. Methyl violet stain; $\times 1000$.

(Received 5 March 1951) 